Quisve valet verbis tantum qui fingere laudes pro meritis eius possit qui talia nobis pectore parta suo quaesitaque praemia liquit?

(Lucretius, De rerum natura, V, 3-5)

\title{
KURT GÖDEL
}

\author{
*28.4.1906 †14.1.1978
}

An der Universität Wien 1930 zum Dr.phil. promoviert, mit der Dissertation „Die Vollständigkeit der Axiome des logischen Funktionenkalküls", erschienen in dieser Zeitschrift, Bd. 37, 349-360 (1930), und 1933 als Privatdozent habilitiert, mit der Habilitationsschrift , Über formal unentscheidbare Sätze der Principia Mathematica und verwandter Systeme I", erschienen ebenda, Bd. 38, 173-198 (1931).

Mitglied des Institute for Advanced Study in Princeton (USA) 1938, dort seit 1953 Professor. Ehrendoktor der Universitäten Harvard, Wien, Yale.

ERNEUERER DER LOGIK 